\title{
Using Data Envelopment Analysis to Examine Operational Auditing Efficiency in Audited Firms
}

Yahya Kamyabi*1, Maryam Salahinejad²

${ }^{1}$ Department of Accounting, Faculty of Economics and Administrative Sciences, University of Mazandaran, Babolsar, Iran

2Department of Management and Acounting, Faculty of Humanities, Islamic Azad University, Ayatollah Amoli Branch, Amol, Iran

*Corresponding Author E-mail: ykamyabi@yahoo.com

Received: 19 December 2019,Revised: 27 January 2020,Accepted: 10 March 2020

\begin{abstract}
Operational auditing is an independent review including all aspects of an organization and an operational auditor has an overall objective to assess the quality of internal controls including its effectiveness and efficiency of operations, reliability of the financial reporting, and compliance with applicable laws and regulations. Operational auditing determines to what extent the manager has used the most efficient resources to achieve the most effective results. The aim of the research is to study whether applying risk-based audit would lead to increase the auditing efficiency process in operational auditing. In this research, Data Envelopment Analysis (DEA) technique has been used to measure the efficiency. We can calculate the efficiency by some inputs or outputs in DEA method. To compare the obtained efficiency of operational auditing by DEA, inferential, non-parametric (or distribution free) statistical tests are used. SPSS and LINGO software and Compare Means are used to measure the efficiencies in the research. T-test results for average efficiency comparison have been divided to both model and non-model states and show that the risk-based average efficiency is significantly more than the non-model state. It is therefore concluded that applying risk-based auditing model can increase operational auditing efficiency process in output-oriented method.
\end{abstract}

Keywords: Using Data Envelopment, Operational Auditing Efficiency, Audited Firms.

\section{Introduction}

Rapid technological advances and intense competition in markets have caused the managers to open a serious account on obtaining and maintaining suitable condition in the markets in recent years. The management has increasing emphasis on effectiveness, efficiency and economy savings of the organization's operations. The manager's informational needs are increasing due to changing internal and external of organizations environments (Colbert, 200). It appears that the only 
data inserted in financial statements would not meet the managers' information needs. The economic units follow the information to judge about the operation quality which finally leads them to make a progress. Not only is the measurement criteria in these kinds of reports not Rial, but also the work hours, the weight components, the number of customers, the number of dismissed staffs and etc., by which the managers are enabled to control and guide business unit (Bakhtiari, 2007; Cosserat, 2007). Due to failure in meeting the managers' information needs, they were driven to obtain more information in the public and private sectors in order to assess and judge about the operation quality and operational advances. Internal auditing and consequently the operational auditing were introduced in this circumstance. Operational auditing is a clear example about the management consulting services which are posed by auditors in consulting services formats and it may have some features of auditing financial statements (Kamyabi and Devi, 2011, 2012). This auditing includes the study of the organization operations or the specified section in order to measure the achievements to their defined goals.

Theoretically, the organizations should operate effectively and efficiently.. Operational audit is one of internal audit tasks in firms and in companies where there is no operational audit this task is assigned to external consulting firms. The task of operational auditors is to provide reports concerning extent of organization's success to top along with suggestions for improvement of these successes (Arjmandi, 2006). In other words, operational audit provides an independent evaluation of efficiency, effectiveness, and economic saving of businesses' activities. Operational auditing helps more effectively the organizations by means of determining operational defects and providing practical recommendations and creating positive changes to follow their way to advance. Operational auditing has special emphasis on the key activities of an organization. The measurement performance criteria are activity-based and use financial and non-financial criteria to measure the performance. As a result of this evaluation, operational auditing is seeking to identify the weak points of the operation and provide some recommendations for improving the performance.

Based on the conducted analysis, the operational auditing was the first organization which established operational auditing topic as an auditing aspect and management consulting services in Iran. In this regard, having established Operational Auditing Committee in 1997 and several year studies and research in this field, Operational Auditin Institution was constituted in 2002 and its implementation is valid up to now. It is in accordance with charter of Auditing Organization which was regarded as the first trustee of operational auditing in public sector with scientific approach and based on the last common standards in the world.

In our country, the major economy resources are dedicated to the state and its management quality has a vital role in economy conditions (Kamyabi and Devi, 2012). There are always many questions about why state companies suffer from losses, why the state projects are delayed, why limited and scarce resources easily suffer from a loss (Kamyabi and Devi, 2012). It appears that some factors in public sector have increasing needs to operational auditing techniques to assess the efficiency, effectiveness and the economy savings of the organizations 
operations. The central emphasis is focused on the principal activities in operational auditing. The performance measurement criteria are activity-based and financial and non-financial scales are used to measure the performance. As a result of this measurement, operational auditing seeks to identify the weak points and recommends suggestions to improve the performance. Since the operational auditing has a wider range than financial statements auditing, the auditors have been faced with more challenges.

The researchers' main focus is dedicated to the performance of the operational auditing projects since the most important factor in keeping the units active is improvement of their efficiency levels (Pickett, 2006). In our competitive world, the efficient use of the resources is inevitable. In fact, this study tries to introduce the operational auditing comprehensively, the implementation framework based on the recent common standards in the world and dealing with risk-based auditing. Since the creativity in this research for measuring risk-based auditing model in operational auditing is based upon DEA, this technique can provide more suitable base for measuring the performance.

\section{Theoretical Concepts and Literature Review}

\section{Audit Risk Management}

To identify risks, providing a mathematical model and the strategic viewpoint for conducting operational auditing is offered. Control risk is the only system-based model which has the most important issue to the auditors. But more risks would be important in the risk-based model to the auditors (Pickett, 2006; Dittenhofer, 2001). Audit risk management means the managing and controlling of the
Acceptable Auditing Risks in order to achieving the highest required level of assurance. The auditor, in this approach, should accepts a level of auditing risk as an acceptable auditing risk and conduct the audit based on it or plan and implement the accepted assurance level (Arjmandi, 2006, 2008).

\section{Operational Auditing}

Operational auditing is a useful tool for guiding the firms toward their goals (Whitington and pany, 1998). In our country, the state runs the major part of the economy resources and its management quality has essential influence on the country. The public sector managers and their agents must provide and use reliable information to be responsive to people. The nature of public sector requires that operational auditing to deal with financial statements and comment in principles framework. Besides, it must be obligatory to implement the financial auditing criteria. So, while it is necessary for auditors to utilize the specialist services in various fields, they should evaluate the managements' decisions and offer their corrective suggestions to improve the management as much as possible. The operational auditing provides information to improve the state responsibility and to facilitate decisions making by the units who responsible for administration and implementing corrective actions (Pollitt, 2006). Operational auditing has various purposes including the evaluation of efficiency, effectiveness and economy savings of the organizations' operations, the evaluation of internal controls, allegiance law and other regulations and identify the opportunities and/or offer suggestions to improve the operations (Bostick and Luehlifing, 2007; GAO, 2007). 
Operational auditing has multiple work areas. It may include the evaluation of all important organization operations (Kreklow, 2007). It is often impossible to separate goals from each other in operational auditing, since all the goals interact with each other. Using internal control approach, all the goals become the aims of internal control system. Also, operational auditing includes various dealing methods like different levels of analysis, research or evaluation which generally result in findings, results and suggestions published in reports. Operational auditors should prepare enough and appropriate documents to reach their goals. Their required documents and related tests levels which are based on the auditing aims are completely different.

\section{Standards of Operational Auditing}

According to the last GAO Standards published in 2007, the standards of operational auditing include the general standards, implementing the operation and reporting. They also must consider ethical implications during their professional responsibility. The foresaid standards are:

-The auditors' ethical implications including public interest, professional behavior, integrity, objectivity, applying information, resources and governmental opportunities suitably.

\section{The general standards}

General standards include the terms of the auditing firms' staff, the independence of the audit firm and auditors, professional supervision and establishing quality control. These standards are practical in all auditing firms including governmental and non-governmental which are responsible for auditing programs, activities and responsibilities of governmental agencies and nonprofit organizations.
Operation implementation standards include planning, supervision, managerial controls, obtaining enough documents and evidences.

Reporting standards include written report, providing report on time, report content, report presentation, report distribution.

\section{Risk-Based Auditing in Operational Auditing}

This model is provided to coordinate the manner of the work time and audit fees based on the framework of operational auditing and applying the scientific methods to planning and estimating of work hour and audit fees (Graham and Messier, 2006; Hunton et al., 2004). The model tries to apply the basic concepts related to risk-based planning and activity as much as possible and also using relationships and related mathematical models in order to improve the auditors' professional judgments with respect to efficiency and observing related auditing standards and consequently; the condition is provided for efficiency improvement, economy savings of auditing operations and the possibility for more effective control on foresaid operations. To conduct the operational auditing standards in governmental sector (common in the international level), auditing operations should be suitably planned and supervised and enough, accepted and related evidences should be obtained to provide a reasonable foundation for the auditors' findings and results. In addition, the auditing operations designing should be in a manner which creates a reasonable confidence level to detect the important violations and frauds.

\section{Theoretical Basis for Model}


As a general principle, according to the conducting operational auditing framework, we can say that there is always a fixed relationship between the risk and the importance and the evidence of auditing (Naidoo, 2002). With regard to this relationship, the level of auditing evidence (in terms of qualitative and quantitative) depends on the importance level and the acceptable auditing risk (AAR). Except for the importance of auditing, when the accepted auditing risk level increase, the accepted confidence level of the auditor's decreases and vice versa. As the importance level to be assumed fixed, the auditors would accept less importance level in proportion to increased accepted auditing confidence level and as a result, they are obliged to collect less auditing evidences (quantitative and qualitative) and vice versa. In addition, there is an adverse relationship between the Acceptable Auditing Risk and Planned Test of Details Detection Risk (PTDDR). It means as the AAR increases, the level of (1-PTDDR) decreases. If we assume that the importance level is fixed, as the foresaid level increases, the amount of the auditing evidences would increase and vice versa.

The required time for the suitable control test is depending on the primary estimation of Cooper. charnes. rohdes (CCR). As the CR evaluation equals with $100 \%$, it is obvious that there is no need to suitable control test and when the CR evaluation equals with $30 \%$, the suitable control test must be conduct at the highest level.

With regard to what stated above, after calculating of the importance level in the unit level and in various activities level based on the auditing strategy note, the estimation time for collecting enough, accepted and related evidences depend on the elementary auditors' estimations about CR and PTDDR. In other word, the calculation of required time in order to conducting evaluation performance and completing auditing operations are depending on the elementary evaluation auditors from PTDDR.

Hypothesis: Applying risk-based auditing in operational auditing causes the audit efficiency process to increase.

\section{Methodology}

This study followed a library research method. This method was used to describe the research background of library method (examination of documents and evidences of audit records) including conceptualization through the examination of scientific articles, books, reports and information available in libraries, information networks and reliable internet databases. Field data and information were used to measure "efficiency" component index by DEA technique. The research aimed to measure the efficiency risk-based operational auditing. Efficiency is one of the most components of proficiency and DEA is applied to measure it in the research. In DEA method, the efficiency of several input and output can be calculated together. We focus on audit organization and audit firms due to the fact that the most important operational auditing projects are implemented by them. In this project, the real data obtained from operational auditing (the completed audit projects with no model or based on risk) are used, inputs and outputs of the projects are extracted and then the efficiency of every project is calculated by DEA technique and they finally are examined by statistical tests. The current research is longitudinal or multi-sectional. Statistical population in this research is operational auditing projects According to the conducted surveys, operational 
auditing firms and audit organizations are the first organizations which formally, and according to the charter, are responsible for the governmental organizations or institutions' operational auditing which has been introduced by government or authorities since 2003. Besides, according to the claims by some audit firms about the providing operational audit services, the researcher's understanding of the statistical population completely refers to these institutions and he tries to complete his understanding about the statistical population. But except for operational auditing firm- audit organization, no firm has conducted operational auditing with the same approach used in this research (based on the last common audit standards of the world).

\section{Research Model}

Data Envelopment Analysis (DEA) is one of the techniques of mathematical programming which is used for performing evaluation in units with similar duties (Pulas \& Jaykas, 2002). Pulas and Jaykas (2000) carried out a study on the efficiency of 36 Greece telecommunication companies in 1998. They defined 2 input and output variables group in their research. Using 2 variable groups and DEA technique which is a mathematical programming technique based on a Farel Studies in 1957, they compared the efficiency of Greece telecommunication units. The results showed that the efficiency of 15 units were obtained 1 and were identified as efficient units and the rest of the companies were regarded as deficient units .

Fathi (1991) compared the performance evaluation of the colleges of the University of Science and Technology with each other. In this research, Data Envelopment Analysis (DEA) mathematical programming model and Analytical
Hierarchy Process (AHP) were applied. DEA compares the colleges initially, followed by obtaining paired comparisons which are fed in dihedral hierarchy of AHP model. Finally, the efficiency and deficiency of different colleges are determined.

The CCR model is the model used in this research which evaluates DMUs assuming constant returns to scale measure. We can consider CCR model in 2 methods or orientations. The first orientation of the model is input-oriented and the second one is output-oriented and both them can be solved in two ways. The first way is the primary problem solution and the secondary problem solution by CCR. In essence, these 2 methods are the same and result in the same answer. The only difference is the way of regarding them. If we solve one of them, it means we solve the other. So, there is no need to solve the problem by both solutions and one method would be enough. If we regard multiple models as the first model in solving DEA linear programming, the envelope model would be the second model. In this research, after obtaining the units' efficiency by dual models, the efficient units will be ranked by this model. The limitation related to the unit is deleted and then the model is solved during ranking of the units and this issue is the only difference in it. The obtained result determines the ranking efficient unit between the other efficient units.

\section{Data analysis}

\section{Estimation of Operational Auditing Projects using DEA}

Real-time data, calculation of real cost based on real time (attachment) and the number of audit team as inputs of operational auditing process, the number of weak points and recommendations in 
audit reports as outputs of operational auditing process in performance evaluation are determined by DEA technique. The above data are collected by the examination of audit projects records, office and archival documents (documentation). The researcher of audit records has examined 35 implemented operational auditing projects by operational auditing firms and audit organization from 2013 to the end of September 2019 and has extracted the above data from the mentioned cases. The most important extracted information includes real-time, calculation of real cost based on real time (attachment) and the number of audit team as inputs of operational auditing process, the number of weak points and recommendations in audit reports.

\section{Research Models' Results}

DEA model measures the relative efficiency through dividing total weighted outputs into total weighted inputs regarding the limitations. To maximize the efficiency by LINGO software, 2 methods are applied in this research. One method is to put the fraction denominator equals with one and maximize the numerator according to $\sum \mathrm{VI}=1$ (input-oriented). The other method is to assume the numerator one and minimize the denominator according to $\sum \mathrm{VI}=0$ (output-oriented). In the first method, the maximum efficiency is one and the minimization is its goal. So, the efficiency of the efficient units and deficient units are less than one in the first method. But in the second method, the minimum efficiency is bigger than one. The obtained unit's efficiency (operational auditing case number one) is $0 / 52$ after solving the model. Thus, the unit is identified as deficient.

\section{Result}

The results of this research are obtained by using the both models of CCR inputoriented and output-oriented and we deal with CCR output-oriented results. We have used the model by its multiple methods and have calculated the units' efficiencies by that. This model has solved 35 different operational auditing cases in 35 different times through LINGO software and the results are as follows. The tables below show the efficiency and ranking of the different cases in this model.

Table 1. Efficiency of Operational Auditing Cases of CCR Model (Input-oriented) in Audit Organization

\begin{tabular}{ccccc}
\hline Row & $\begin{array}{c}\text { The audited } \\
\text { firm }\end{array}$ & $\begin{array}{c}\text { Audit } \\
\text { process }\end{array}$ & The calculated efficiency rate & $\begin{array}{c}\text { The pattern } \\
\text { firms }\end{array}$ \\
\hline 1 & 1 & No model & 0.52 & $22-26$ \\
2 & 2 & No model & 0.62 & 22 \\
3 & 3 & No model & 0.18 & $22-33$ \\
4 & 4 & No model & 0.5 & 26 \\
5 & 5 & No model & 0.3 & 22 \\
6 & 6 & No model & 0.71 & 22 \\
7 & 7 & No model & 0.62 & $22-26$ \\
8 & 8 & No model & 0.57 & 33 \\
9 & 9 & No model & 0.34 & $22-33$ \\
10 & 10 & No model & 0.44 & 33 \\
11 & 11 & Risk-based & 0.73 & 33
\end{tabular}




\begin{tabular}{|c|c|c|c|c|}
\hline 12 & 12 & Risk-based & 0.5 & $22-33$ \\
\hline 13 & 13 & Risk-based & 0.54 & 33 \\
\hline 14 & 14 & Risk-based & 0.61 & 33 \\
\hline 15 & 15 & Risk-based & 0.85 & $22-33$ \\
\hline 16 & 16 & Risk-based & 0.53 & 22 \\
\hline 17 & 17 & Risk-based & 0.61 & $26-33$ \\
\hline 18 & 18 & Risk-based & 0.57 & $22-33$ \\
\hline 19 & 19 & Risk-based & 0.68 & 33 \\
\hline 20 & 20 & Risk-based & 0.58 & $22-33$ \\
\hline 21 & 21 & Risk-based & 0.63 & $22-33$ \\
\hline 22 & 22 & Risk-based & 1 & 22 \\
\hline 23 & 23 & Risk-based & 0.73 & $22-33$ \\
\hline 24 & 24 & Risk-based & 0.67 & $22-33$ \\
\hline 25 & 25 & Risk-based & 0.65 & $22-33$ \\
\hline 26 & 26 & Risk-based & 1 & 26 \\
\hline 27 & 27 & Risk-based & 0.7 & $22-26$ \\
\hline 28 & 28 & Risk-based & 0.89 & 22 \\
\hline 29 & 29 & Risk-based & 0.74 & $22-33$ \\
\hline 30 & 30 & Risk-based & 0.83 & $22-26-33$ \\
\hline 31 & 31 & Risk-based & 0.68 & $22-26$ \\
\hline 32 & 32 & Risk-based & 0.71 & $22-33$ \\
\hline 33 & 33 & Risk-based & 1 & 33 \\
\hline 34 & 34 & Risk-based & 0.86 & $22-33$ \\
\hline 35 & 35 & Risk-based & 0.75 & $22-33$ \\
\hline
\end{tabular}

There is a model called "AndersonPeterson" model which is able to rank the one-grade efficient units and select the most efficient one. Table 2 below shows the results obtained from Anderson-Peterson model by LINGO software.

\section{Results obtained from CCR Model (Output-Oriented)}

This model, also, is solved for 35 operational auditing cases of audit organization by 35 different times through LINGO software like previous model and the results are as follows.

To solve this model, LINGO software is used and the unit's efficiency and the amount related to inputs and outputs weight and also the related quantities to $S$ variables are calculated. After solving the model, the obtained efficiency of the unit is 1.93 (operational auditing case number one). So, the unit is regarded as a deficient unit.

Table 2. Results of Anderson-Peterson Model for CCR Model (Input-Oriented)

\begin{tabular}{cccc}
\hline Row & The audited firm & Audit process & $\begin{array}{c}\text { The calculated efficiency } \\
\text { rate }\end{array}$ \\
\hline 1 & 22 & Risk-based & 1.32 \\
2 & 26 & Risk-based & 1.13
\end{tabular}


Table 3. Efficiency of Operational Auditing Cases of CCR Model (Output-Oriented) in Audit Organization

\begin{tabular}{|c|c|c|c|c|}
\hline Row & The audited firm & Audit process & The calculated efficiency rate & The pattern firms \\
\hline 1 & 1 & No model & 1.93 & $22-26$ \\
\hline 2 & 2 & No model & 1.61 & 22 \\
\hline 3 & 3 & No model & 5.57 & $22-33$ \\
\hline 4 & 4 & No model & 1.98 & 26 \\
\hline 5 & 5 & No model & 3.3 & 22 \\
\hline 6 & 6 & No model & 1.41 & 22 \\
\hline 7 & 7 & No model & 1.61 & $22-26$ \\
\hline 8 & 8 & No model & 1.75 & 33 \\
\hline 9 & 9 & No model & 2.91 & $22-33$ \\
\hline 10 & 10 & No model & 2.25 & 33 \\
\hline 11 & 11 & Risk-based & 1.36 & 33 \\
\hline 12 & 12 & Risk-based & 2.02 & $22-33$ \\
\hline 13 & 13 & Risk-based & 1.84 & 33 \\
\hline 14 & 14 & Risk-based & 1.64 & 33 \\
\hline 15 & 15 & Risk-based & 1.17 & $22-33$ \\
\hline 16 & 16 & Risk-based & 1.9 & 22 \\
\hline 17 & 17 & Risk-based & 1.63 & $26-33$ \\
\hline 18 & 18 & Risk-based & 1.77 & $22-33$ \\
\hline 19 & 19 & Risk-based & 1.47 & 33 \\
\hline 20 & 20 & Risk-based & 1.72 & $22-33$ \\
\hline 21 & 21 & Risk-based & 1.59 & $22-33$ \\
\hline 22 & 22 & Risk-based & 1 & 22 \\
\hline 23 & 23 & Risk-based & 1.28 & $22-33$ \\
\hline 24 & 24 & Risk-based & 1.49 & $22-33$ \\
\hline 25 & 25 & Risk-based & 1.55 & $22-33$ \\
\hline 26 & 26 & Risk-based & 1 & 26 \\
\hline 27 & 27 & Risk-based & 1.43 & $22-26$ \\
\hline 28 & 28 & Risk-based & 1.13 & 22 \\
\hline 29 & 29 & Risk-based & 1.34 & 22-33 \\
\hline 30 & 30 & Risk-based & 1.2 & $22-26-33$ \\
\hline 31 & 31 & Risk-based & 1.48 & $22-26$ \\
\hline 32 & 32 & Risk-based & 1.41 & $22-33$ \\
\hline 33 & 33 & Risk-based & 1 & 33 \\
\hline 34 & 34 & Risk-based & 1.16 & $22-33$ \\
\hline 35 & 35 & Risk-based & 1.34 & $22-33$ \\
\hline
\end{tabular}

Table 4. Audit Firm's Operational Auditing Cases for CCR Model by Anderson-Peterson Model (Output-Oriented)

\begin{tabular}{cccc}
\hline Row & The audited firm & Audit process & $\begin{array}{c}\text { The calculated efficiency } \\
\text { rate }\end{array}$ \\
\hline 1 & 22 & Risk-based & 0.95 \\
2 & 26 & Risk-based & 0.89 \\
3 & 33 & Risk-based & 0.76 \\
\hline
\end{tabular}


The efficiency results of different operational auditing cases by 4 used models are as follows:

Table 5. A Summary of the efficiency results of the research operational auditing cases

\begin{tabular}{|c|c|c|c|c|c|c|}
\hline row & $\begin{array}{c}\text { The } \\
\text { operational } \\
\text { audited firm }\end{array}$ & $\begin{array}{c}\text { Audit } \\
\text { process }\end{array}$ & $\begin{array}{c}\text { CCR input- } \\
\text { oriented }\end{array}$ & $\begin{array}{l}\text { CCR output- } \\
\text { oriented }\end{array}$ & $\begin{array}{c}\text { Total } \\
\text { efficient }\end{array}$ & $\begin{array}{c}\text { Total } \\
\text { deficient }\end{array}$ \\
\hline 1 & 1 & No model & deficient & Deficient & 0 & 2 \\
\hline 2 & 2 & No model & deficient & Deficient & 0 & 2 \\
\hline 3 & 3 & No model & deficient & Deficient & 0 & 2 \\
\hline 4 & 4 & No model & deficient & Deficient & 0 & 2 \\
\hline 5 & 5 & No model & deficient & Deficient & 0 & 2 \\
\hline 6 & 6 & No model & deficient & Deficient & 0 & 2 \\
\hline 7 & 7 & No model & deficient & Deficient & 0 & 2 \\
\hline 8 & 8 & No model & deficient & Deficient & 0 & 2 \\
\hline 9 & 9 & No model & deficient & Deficient & 0 & 2 \\
\hline 10 & 10 & No model & deficient & Deficient & 0 & 2 \\
\hline 11 & 11 & Risk-based & deficient & Deficient & 0 & 2 \\
\hline 12 & 12 & Risk-based & deficient & Deficient & 0 & 2 \\
\hline 13 & 13 & Risk-based & deficient & Deficient & 0 & 2 \\
\hline 14 & 14 & Risk-based & deficient & Deficient & 0 & 2 \\
\hline 15 & 15 & Risk-based & deficient & Deficient & 2 & 2 \\
\hline 16 & 16 & Risk-based & deficient & Deficient & 0 & 2 \\
\hline 17 & 17 & Risk-based & deficient & Deficient & 0 & 2 \\
\hline 18 & 18 & Risk-based & deficient & Deficient & 0 & 2 \\
\hline 19 & 19 & Risk-based & deficient & Deficient & 0 & 2 \\
\hline 20 & 20 & Risk-based & deficient & Deficient & 0 & 2 \\
\hline 21 & 21 & Risk-based & deficient & Deficient & 0 & 2 \\
\hline 22 & 22 & Risk-based & efficient & Efficient & 2 & 0 \\
\hline 23 & 23 & Risk-based & deficient & Deficient & 0 & 2 \\
\hline 24 & 24 & Risk-based & deficient & Deficient & 0 & 2 \\
\hline 25 & 25 & Risk-based & deficient & Deficient & 0 & 2 \\
\hline 26 & 26 & Risk-based & efficient & efficient & 2 & 0 \\
\hline 27 & 27 & Risk-based & deficient & deficient & 0 & 2 \\
\hline 28 & 28 & Risk-based & deficient & deficient & 0 & 2 \\
\hline 29 & 29 & Risk-based & deficient & deficient & 0 & 2 \\
\hline 30 & 30 & Risk-based & deficient & deficient & 0 & 2 \\
\hline 31 & 31 & Risk-based & deficient & deficient & 0 & 2 \\
\hline 32 & 32 & Risk-based & deficient & deficient & 0 & 2 \\
\hline 33 & 33 & Risk-based & efficient & efficient & 2 & 0 \\
\hline 34 & 34 & Risk-based & deficient & deficient & 0 & 2 \\
\hline 35 & 35 & Risk-based & deficient & deficient & 0 & 2 \\
\hline 66 & 6 & & & total & & \\
\hline
\end{tabular}

Four operational auditing projects analysis were done by inferential statistics.
One required assumption for using student's T-test is the normality of the observations which is examined by 
Kolmogorov-Smirnov test and the related results are as follows:

Table 6. Efficiency Results of Different Operational Auditing Cases

\begin{tabular}{|c|c|c|c|c|}
\hline row & $\begin{array}{l}\text { The operational } \\
\text { audited firm }\end{array}$ & Audit process & $\begin{array}{l}\text { Input-oriented } \\
\text { calculated } \\
\text { efficiency rate }\end{array}$ & $\begin{array}{l}\text { Output-oriented } \\
\text { calculated } \\
\text { efficiency rate }\end{array}$ \\
\hline 1 & 1 & No model & 0.52 & 1.93 \\
\hline 2 & 2 & No model & 0.62 & 1.61 \\
\hline 3 & 3 & No model & 0.18 & 5.57 \\
\hline 4 & 4 & No model & 0.5 & 1.98 \\
\hline 5 & 5 & No model & 0.3 & 3.3 \\
\hline 6 & 6 & No model & 0.71 & 1.41 \\
\hline 7 & 7 & No model & 0.62 & 1.61 \\
\hline 8 & 8 & No model & 0.57 & 1.75 \\
\hline 9 & 9 & No model & 0.34 & 2.91 \\
\hline 10 & 10 & No model & 0.44 & 2.25 \\
\hline 11 & 11 & Risk-based & 0.73 & 1.36 \\
\hline 12 & 12 & Risk-based & 0.5 & 2.02 \\
\hline 13 & 13 & Risk-based & 0.54 & 1.84 \\
\hline 14 & 14 & Risk-based & 0.61 & 1.64 \\
\hline 15 & 15 & Risk-based & 0.85 & 1.17 \\
\hline 16 & 16 & Risk-based & 0.53 & 1.9 \\
\hline 17 & 17 & Risk-based & 0.61 & 1.63 \\
\hline 18 & 18 & Risk-based & 0.57 & 1.77 \\
\hline 19 & 19 & Risk-based & 0.68 & 1.47 \\
\hline 20 & 20 & Risk-based & 0.58 & 1.72 \\
\hline 21 & 21 & Risk-based & 0.63 & 1.59 \\
\hline 22 & 22 & Risk-based & 1 & 1 \\
\hline 23 & 23 & Risk-based & 0.73 & 1.28 \\
\hline 24 & 24 & Risk-based & 0.67 & 1.49 \\
\hline 25 & 25 & Risk-based & 0.65 & 1.55 \\
\hline 26 & 26 & Risk-based & 1 & 1 \\
\hline 27 & 27 & Risk-based & 0.7 & 1.43 \\
\hline 28 & 28 & Risk-based & 0.89 & 1.13 \\
\hline 29 & 29 & Risk-based & 0.74 & 1.34 \\
\hline 30 & 30 & Risk-based & 0.83 & 1.2 \\
\hline 31 & 31 & Risk-based & 0.68 & 1.48 \\
\hline 32 & 32 & Risk-based & 0.71 & 1.41 \\
\hline 33 & 33 & Risk-based & 1 & 1 \\
\hline 34 & 34 & Risk-based & 0.86 & 1.16 \\
\hline 35 & 35 & Risk-based & 0.75 & 1.34 \\
\hline
\end{tabular}

Table 7. Results of the Average Efficiency Comparison in Both Groups of Model and Non-Model in CCR Input-Oriented Method

\begin{tabular}{ccccccc}
\hline Group & Number & Mean & $\begin{array}{c}\text { Standard } \\
\text { deviation }\end{array}$ & $\begin{array}{c}\text { Degree of } \\
\text { freedom }\end{array}$ & t-value & p-value \\
\hline Non-model & 10 & $0 / 48$ & $0 / 16$ & 33 & $-4 / 25$ & $0 / 000$ \\
& & & & & & $60 \mid$ Page
\end{tabular}




$\begin{array}{llll}\text { Risk-based } & 25 & 0 / 72 & 0 / 15\end{array}$

Table 7 shows the t-value results in both groups in CCR input-oriented and demonstrates that the average efficiency equals with $0 / 48$ with $0 / 16$ SD in non-model and $0 / 72$ with $0 / 15$ SD in risk-based model which is a statistically significant relationship between the average efficiency of both groups (p-value<0/05). The risk-based average efficiency is more than the nonmodel average efficiency. Thus, we can conclude that applying the risk-based operational auditing can increase the efficiency of operational auditing process in output-oriented model.
Table 8 shows the t-value results in both groups in CCR out-oriented and demonstrates that the average efficiency equals with $1 / 44$ with $0 / 28$ SD in non-model and $2 / 43$ with $1 / 25$ SD in risk-based model which is a statistically significant relationship between the average efficiency of both groups (p-value<0/05). The risk-based average efficiency is more than that of the non-model one. Thus, we can conclude that applying the risk-based operational auditing can increase the efficiency of operational auditing process.

Table 8. Results of the Average Efficiency Comparison in Both Groups of Model and Non-Model in CCR Output-Oriented Method

\begin{tabular}{ccccccc}
\hline Group & Number & Mean & $\begin{array}{c}\text { Standard } \\
\text { deviation }\end{array}$ & $\begin{array}{c}\text { Degree of } \\
\text { freedom }\end{array}$ & t-value & p-value \\
\hline Non-model & 25 & $1 / 44$ & $0 / 28$ & 33 & $3 / 80$ & $0 / 001$ \\
Risk-based & 10 & $2 / 43$ & $1 / 25$ & & & \\
\hline
\end{tabular}

\section{Discussion and Conclusion}

The main purpose of this research is examining the risk-based auditing model in operational auditing. The research tests the model's efficiency by Data Envelopment Analysis (DEA) technique. This model is a programming tool which helps the auditors to plan and implement the audits in a manner that keeps the reliable level during the auditing process. The model was implemented in 25 operational auditing projects conducted by operational auditing firms and operational organizations. Then, the obtained efficiency of the 25 projects were compared with the similar data obtained from 10 auditing projects implemented without this model and finally the related tests were done. The findings are as follows:

T-test results for average efficiency in groups of non-model and model in CCR inputoriented method demonstrate that the average efficiency in non-model method is $0 / 48$ with $0 / 16 \mathrm{SD}$ and in risk-based is $0 / 72$ with $0 / 15$ SD. The difference in average efficiency is significant between the two groups ( $\mathrm{p}$-value $<0 / 05$ ), so that the risk-based average efficiency is significantly more than the non-model method. As a result, it can be concluded that the risk-based auditing model can increase the efficiency operational auditing process.

T-test results for average efficiency in groups of non-model and model in CCR outputoriented method demonstrate that the average efficiency in non-model method is $1 / 44$ with $0 / 28 \mathrm{SD}$ and in risk-based is $2 / 43$ with $1 / 25$ SD. The difference in average efficiency is significant between the two groups ( $p$-value $<0 / 05)$. Consequently, the risk-based average efficiency is significantly more than the non-model method. Accordingly, it can be stated that the riskbased auditing model can increase the 
efficiency operational auditing process in an output-oriented method.

According to the obtained results, inputoriented and output-oriented are efficient and the rest are deficient in CRR method.

\section{References}

Arjmandi, R. (2006). How to implement operational auditing, Operational auditing firm, 20: 423-459.

Arjmandi, R. (2008). Audit risk management, Tehran: Moein Publication.

Bakhtiari, M. (2007). Operational Auditing. Accountant Journal, 57: 521-542.

Bostick, l, Luehlifing, M. (2007). Auditors Responsibilities Formalized Under SAS 109, CPA Journal. 17: 252-271.

Colbert, J. (2000). International and US Standards: error and fraud, Managerial Auditing Journal. 22: 145-185.

Cosserat, G. W. (2007). Modern Auditing, New York: John Wiley \& Sons, Inc.

Dittenhofer, M. (2001). Performance Auditing in Governments, Journal of Managerial Auditing, 20,: 421-445.

Fathi, A.A. (1991). A Comparison of the Performance Status of the Faculties of Science and Technology University, MA thesis in Industrial Engineering, University of Science and Technology, Tehran.
Graham, L, Messier, W. (2006). Audit Risk and Materiality in Conducting an Audit, Journal of Accountancy, 35: 325-352.

\section{.(2007). Generally Accepted} Government Auditing Standards, Washington: United States Government Accountability Office.

Hunton, J. E, Bryant, S. M, Bagranoff, N .A. (2004). Information Technology Auditing, , New York: John Wiley \& Sons, Inc.

Kreklow, S. (2007). Improving organizational performance audits, Journal of government finance review, 54,: 185-201.

Kamyabi, Y, Devi, S. (2011). Outsourcing of accounting functions in the context of SMEs in emerging economies, Australian Journal of Basic and Applied Sciences. 5: 1696-1703.

Kamyabi, Y, Devi, S. (2012). The impact of advisory services on Iranian SME performance: An empirical investigation of the role of professional accountants, South African Journal of Business Management, 43: 61-72.

Naidoo, S. (2002). Managing Risk and Organizational Performance, Journal of Accounting and Tax Periodicals, 14: 296-321.

Pollitt, C. (2006). Performance information for democracy: The Missing Link?, Evaluation, 12: 38-55.

Pickett, F. (2006). Audit Planning: a Risk- based Approach, , New York: John Wiley \& Sons, Inc.

Whitington, R, Pany, k, (1998). principle of auditing and other assurance services, New York: mcgrawhill.

How to cite this article: Yahya Kamyabi, Maryam Salahinejad, Using Data Envelopment Analysis to Examine Operational Auditing Efficiency in Audited Firms. International Journal of Advanced Studies in Humanities and Social Science, 2020, 9(1), 50-62. http://www.ijashss.com/article 105615.html 